\title{
Effects of Massage on Cardiovascular Outcomes and Perceived Exer- tion of Brazilian JIU-JITSU Parathletes Submitted to Simulated Fight
}

\author{
Jaqueline Santos Silva Lopes ${ }^{1,3 *}$, Simone Maria Lopes ${ }^{1}$, Aníbal Monteiro de Magalhães \\ Neto $^{2}$, Aline Castilho de Almeida 4 , Abel Pompeu de Campos Júnior ${ }^{1}$, Bruno Fernando \\ Cruz Luccheti ${ }^{1}$, Daianne Camargos da Silva ${ }^{1}$, Claudia Marlise Balbinotti Andrade ${ }^{3}$
}

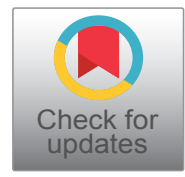

${ }^{1}$ University Center of the Araguaia Valley (UNIVAR), Department of physiotherapy, Barra do Garças, Brazil

${ }^{2}$ Federal University of Mato Grosso (UFTM), Postgraduate program in immunology and applied parasitology, department of physical education (PPGIP), MT, Brazil

${ }^{3}$ Federal University of Mato Grosso (UFTM), Postgraduate Program in Health Sciences (PPGSC), MT, Brazil

${ }^{4}$ Federal University of São Carlos (UFSCAR), Department of physiotherapy, São Carlos, SP, Brazil

*Corresponding author: Jaqueline Santos Silva Lopes, Department of Physiotherapy, University Center of the Araguaia Valley (UNIVAR), Barra do Garças, R. Moreira Cabral, $n^{\circ} 1000$ - Barra do Garças/ Mato Grosso, CEP: 78600-000, Brazil, Tel: +55-(66)-9-8441-7159

\begin{abstract}
The aim of this study was to investigate the cardiovascular physiological responses and perceived exertion rate on Brazilian Jiu-Jitsu parathletes submitted to a simulated fight. Six male athletes were included. After the fight, a recuperative massage protocol was applied to the upper limbs and trunk. Regarding Heart Rate (HR), values above baseline were found in all participants post intervention. Only one participant demonstrated recovery of Blood Pressure (BP) to baseline after the technique. Outcomes related to perceived exertion, measured immediately after the simulated fight, showed an average value of 8.8 , which indicates perception of strenuous effort, near maximum levels. In conclusion, cardiovascular parameters did not return to baseline after intervention and strenuous perceived exertion was reported by the participants.
\end{abstract}

\section{Keywords}

Martial arts, Physical exercise, Heart rate, Physiological monitoring

\section{Introduction}

Considered one of the oldest martial arts, Brazilian jiu-jitsu is characterized as a self-defense sport consisting of high intensity anaerobic movements interspersed with low aerobic intensity [1-3]. In ad- dition, it is a contact sport based on throwing an opponent and then controlling or submitting him on the ground through immobilization techniques, such as strangleholds and joint locks $[4,5]$.

It is also a form of social inclusion in sport, represented by the Brazilian Jiu-Jitsu Parasport, practiced by individuals with different levels of physical or mental disability, of acquired or congenital origin [6]. Practitioners develop respect, reasoning, and self-esteem, as well as physiological outcomes on positive cardiorespiratory, functional, clinical, and metabolic parameters.

In this context, due to the higher energy demand required during combat, systemic metabolic and cardiorespiratory alterations occur, such as increased cardiac output and respiratory rate, in order to maintain the necessary blood demand in the various body tissues during sports [7-11].

In this regard, some studies [4,8,12-14] show that the Subjective Perceived Exertion (SPE) corresponds to an indicative parameter related to exercise intensity, stress and extra competition factor, where their levels are able to directly influence the athlete's performance during competition. In this sense, Detanico, et

Citation: Lopes SM, de Magalhães Neto AM, Andrade CMB, de Almeida AC, de Campos Júnior AP, et al. (2019) Effects of Massage on Cardiovascular Outcomes and Perceived Exertion of Brazilian JIU-JITSU Parathletes Submitted to Simulated Fight. Int J Sports Exerc Med 5:156. doi.org/10.23937/24695718/1510156

Accepted: December 14, 2019; Published: December 16, 2019

Copyright: (c) 2019 Lopes SM, et al. This is an open-access article distributed under the terms of the Creative Commons Attribution License, which permits unrestricted use, distribution, and reproduction in any medium, provided the original author and source are credited. 
al. [13] and Andreato, et al. [4] evaluated the intensity of perceived exertion during fights using internal stress load markers by comparing with heart rate and lactate values. Their findings demonstrated a relationship between the SPE and the increment of the physiological markers analyzed.

However, as regards exclusively to Brazilian jiu-jitsu parasport, there are no published studies exploring cardiovascular parameters and perceived exertion resulting from the practice of this sport. In this regard, studies $[6,15]$ attribute a lack of studies on parasport populations due to the logistical difficulty in grouping a large number of parathletes of the same sport.

Therefore, it must be considered that Brazilian jiu-jitsu Parasport has increasing popularity and causes beneficial changes in several biological markers. Such variations allow a new science perspective about this sport, not only considering the interaction between body systems, but also in relation to the physiological and adaptive effects produced, as well as their impacts on sports performance and prevention of injuries in the musculoskeletal system $[12,13]$.

With the numerous changes in body homeostasis caused by the practice of Brazilian jiu-jitsu, using techniques that restore these systems are pertinent, taking into account the intended benefits of early recovery. Thus, the literature investigates the specific effects of recovery techniques such as cold-water immersion, laser therapy, contrast, active and passive recovery, and massage. Among these, massage can be highlighted because it is considered as low cost, easy application and present good scientific results $[16,17]$. Nevertheless, the validity and reliability of the protocols used should be prioritized, since this variable directly interferes with the results obtained $[16,17]$.

Also, regarding the physiological effects of massage, there is increased blood and lymphatic flow, which facilitates the removal and elimination of catabolics, pain relief, decreased tension and muscle spasms, and improved range of motion and flexibility $[18,19]$. The set of described effects associated with the easier logistic related to the massage application, make this method investigation relevant in specific populations, such as
Brazilian Jiu-Jitsu Parasport, which provide data with potential for reflection on clinical use, to promote recovery after exertion.

From the above, the rationale used to formulate the design of this study was based on the implicit need, due to the lack of specific studies that address the population profile mentioned associated with the positive points highlighted about the technique used. Based on the outcomes, it is hypothesized that the scientific basis supports the suggestion of specific intervention protocols, within the scope of recovery and periodization proposed in future studies. Therefore, the aim of this study was to investigate the physiological responses of cardiovascular outcomes and the perceived exertion rate in athletes of Brazilian jiu-jitsu Parasport submitted to a simulated competition fight.

\section{Methods}

\section{Participants}

Six male athletes practicing Brazilian Jiu-Jitsu Parasport participated in this study. The eligibility criteria adopted included the practice of Brazilian Jiu-Jitsu Parasport for a period longer than 6 months. The sample size was characterized by a convenience scenario, attributed to the logistical difficulty in grouping high number of participants with the inclusion characteristics adopted in the study. The anthropometric characteristics of the participants are presented in Table 1.

The sample consisted of four amateur athletes (III, IV, V and VI) and two professional athletes, with recent world titles (I and II). Participants had visual or physical disabilities (Table 2). In addition, all attended the same training center and no musculoskeletal injuries were reported during the study. The anonymity of the participants was guaranteed. There was masking of the participants, researcher and evaluator regarding the results, who were blinded to the hypotheses and outcomes analyzed.

Additional inclusion criteria were absence of anemia, inflammation, diabetes, cardiovascular disease, and musculoskeletal injuries within six months prior to data collection. In addition, the participants were

Table 1: Anthropometric characteristics of participants.

\begin{tabular}{|l|l|l|l|l|l|l|}
\hline & Age (years) & Height $\mathbf{( m )}$ & $\begin{array}{l}\text { Body mass } \\
\mathbf{( k g )}\end{array}$ & $\begin{array}{l}\text { Body mass } \\
\text { index (kg.m } \mathbf{m}^{2}\end{array}$ & $\begin{array}{l}\text { Training time } \\
\text { (years) }\end{array}$ & $\begin{array}{l}\text { Training time per } \\
\text { week (hours) }\end{array}$ \\
\hline Parathlete I & 43 & 1.63 & 96.5 & 36.2 & 22 & 18 \\
\hline Parathlete II & 36 & 1.70 & 82.3 & 28.4 & 7 & 9 \\
\hline Parathlete III & 41 & 1.65 & 90.0 & 33.0 & 1 & 7 \\
\hline Parathlete IV & 34 & 1.76 & 89.0 & 28.7 & 1.2 & 6 \\
\hline Parathlete V & 13 & 1.46 & 35.5 & 16.5 & 0.9 & 5 \\
\hline Parathlete VI & 40 & 1.63 & 84.0 & 31.6 & 0.7 & 6 \\
\hline
\end{tabular}

Legend: $\mathrm{m}=$ meters; $\mathrm{kg}=$ kilograms; $\mathrm{kg} \cdot \mathrm{m}^{2}=$ kilograms per square meter. Parathlete I-II = High Yield; Other Parathletes = amateurs. 
Table 2: Description of the functional classifications and types of injuries in the participating athletes.

\begin{tabular}{|l|l|l|l|l|}
\hline Disability & Functional Classification & Description of injury & N & Rf (\%) \\
\hline $\begin{array}{l}\text { Physical motor } \\
\text { Disability }\end{array}$ & S6 & Amputations of the leg (UL) & 4 & 66.4 \\
\hline $\begin{array}{l}\text { Visual } \\
\text { Disability }\end{array}$ & S12 & Partial visual disability & 2 & 33.3 \\
\hline
\end{tabular}

Legend: $\mathrm{N}=$ number of participants; Rf = Relative Frequency; UL = Upper Limbs; Parathletes I, III, V and IV have physical motor disability. Parathletes II and IV have visual disability.

instructed to abstain from anti-inflammatory medications, analgesics, alcoholic beverages, tobacco and not to perform any exercise not proposed by the study during the data collection period. All subjects followed a similar diet and did not receive any extra supplementation.

\section{Ethics statement}

Participants were informed about the procedures and objectives of the study and, after agreeing, signed the informed consent form, ensuring their privacy. All procedures were previously approved by the Human Research Ethics Committee of the Federal University of Mato Grosso (Araguaia campus, under opinion number: $2,997,241)$. It has been registered in clinical trials to increase the visibility and transparency of procedures performed for the entire scientific community (registration number: NCT03057210).

\section{Study design}

This is a controlled clinical trial. Data collection was performed in September of 2018 at the participants' usual training center (Grace Barra Academy) located in Barra do Garças - MT, Brazil and data analysis was conducted at the Federal University of Mato Grosso (UFMT), Araguaia campus. All procedures were performed under standard ambient conditions (temperature: $28 \pm 1{ }^{\circ} \mathrm{C}$; relative air humidity: $84 \%$ ). Data collection occurred in the morning and participants were instructed to eat a light meal before the procedures.

At first, all participants underwent an anthropometric assessment (Table 1) using a digital scale (Tanita BC554, Iron Man/Inner Scaner, Tanita, Illinois, United States) and a stadiometer (Sanny, American Medical Brazil, São Paulo Brazil). Body mass index [kg: (m2)*1] (BMI) was calculated as BM divided by height squared. Then a simulated fight was performed, followed by the application of a recuperative massage protocol. The assessment of cardiovascular parameters was performed in the pre and post-fight moments. The perceived exertion was measured immediately after the simulated fight was completed.

The order of fights was defined by prior randomization. Warm-up was used with Brazilian jiu-jitsu movements of light-intensity, characterized by low heart rate and low strength requirement, for five minutes. The simulated fight protocol was performed in accor- dance with the rules of the Brazilian Jiu-Jitsu Federation, excluding any type of finalization. In these cases, the athletes were separated and directed to return to the fight immediately. Thus, the maximum effort was recommended as well as similar activity time for all participants. The athletes fought with no disabled athletes, but with similar weights, not included in the study, who were previously trained and oriented on standardized fighting behavior, with all participants, in order to minimize the influence of possible bias.

\section{Procedures}

\section{Perceived exertion}

The subjective perceived exertion (PSE) was assessed using the Perceived Exertion Scale (OMNI-RES) for resistance exercise [20], which consists of an ordinal scale from 0 to 10 , with 0 corresponding to extremely easy and 10 extremely hard. To apply the scale the following question was standardized: "How do you rate the intensity of resistance in the exercise performed now?".

\section{Cardiovascular parameters}

Blood Pressure (BP) was measured in the left arm in the sitting position. Measurements were performed by auscultatory method with a PREMIUM ${ }^{\circledR}$ sphygmomanometer and stethoscope, properly calibrated. (Heart Rate (HR) was also verified by a portable MONTSERRAT ${ }^{\circledast}$ device, under rest and post exertion, in a sitting position.

\section{Massage protocol}

The massage protocol used followed the suggested by Mantovani, et al. [21]. Thus, the was massage performed during 12 minutes, being 6 minutes on the anterior region of the arm ( 3 minutes for each limb) and 6 minutes on the posterior region of the trunk. The choice of these anatomical sites was due to the effort required during this sport and physical characteristics of the participants.

The massage was performed in the supine (for limbs) and ventral (for trunk) position. Surface and deep slip techniques were used, being the deep slip presented in two intensities: moderate or intense, gradually increased during protocol application (1 minute of application at each intensity described). The massage was 
Table 3: Cardiovascular outcomes and perceived exertion.

\begin{tabular}{|c|c|c|c|c|c|c|c|}
\hline \multirow{2}{*}{$\mathbf{P}$} & \multicolumn{2}{|l|}{ Baseline } & \multicolumn{3}{|l|}{ Post Fight } & \multicolumn{2}{|l|}{$\Delta \%$} \\
\hline & HR (bpm) & BP (mmhg) & HR (bpm) & BP (mmhg) & SPE & $\Delta \%$ HR & $\Delta \% B P$ \\
\hline I & 91 & $140 / 100$ & 98 & $140 / 110$ & 7 & & \\
\hline II & 79 & $130 / 90$ & 92 & $160 / 120$ & 9 & & \\
\hline III & 68 & $120 / 80$ & 102 & $140 / 80$ & 8 & 5.8 & 15.0 \\
\hline IV & 81 & $120 / 80$ & 103 & $130 / 60$ & 8 & & \\
\hline V & 71 & $90 / 60$ & 82 & $120 / 90$ & 10 & & \\
\hline VI & 82 & $160 / 100$ & 90 & $150 / 100$ & 10 & & \\
\hline
\end{tabular}

Legend: $\mathrm{P}$ - Parathlete; HR = Heart Rate; BP = Blood Pressure; SPE = Subjective Perceived Exertion; $\Delta=$ Mean change from baseline.

performed towards the muscle fibers, from distal to proximal, following lymphatic flow and venous return.

In addition, for the technique application, the following rhythm was used: $1 \mathrm{~s}$ (second) of slip and $1 \mathrm{~s}$ for return of the hand to the initial position, totaling $2 \mathrm{~s}$ of slip. The described massage rhythm was controlled by an electronic metronome, used by therapists during performance of the technique. To apply the described massage, 2 physiotherapists were previously trained by a professional sports physiotherapist, with expertise in post-exercise recovery in order to standardize the technique application.

\section{Statistical analysis}

Statistical analyzes were conducted using the SPSS vs. 16.0 (IBM, Corp. Armonk, NY, USA). Data normality was initially analyzed by the Komolgorov-Smirnov test, and normal distribution was observed. Comparisons of the variables analyzed between the pre and post protocol period were calculated by the mean of the differences in percentage. Participants had their outcomes analyzed individually. Mean values were verified for perceived exertion.

\section{Results}

The characteristics of the participants are presented in Table 1 and Table 2. Table 3 presents the outcomes values of cardiovascular parameters and perceived exertion.

For HR, values above baseline were found in all participants at post intervention. For BP, it is observed that only participant $\mathrm{VI}$ demonstrated reduction after massage application. The remaining participants maintained values above those observed at baseline. Still, for BP, participants I and VI already showed high values at rest, before the effort (Table 3 ).

Outcomes related to exertion perceived, measured immediately after the simulated fight, showed an average value of 8.8 , which indicates perception of strenuous effort, near maximum levels (Table 3 ).

\section{Discussion}

The present study investigated the physiological responses, represented by cardiovascular outcomes and perceived exertion rate, in Brazilian jiu-jitsu parathletes submitted to the simulated fight followed by a recuperative massage protocol. The analyzed outcomes demonstrate that in the immediate moment after recovery intervention, HR and BP values remained slightly altered. Also, there was a subjective perception of strenuous effort, near maximum levels, measured immediately after the fight.

Regarding the outcome related to the exertion perceived, Carneiro, et al. [11] evaluated the HR behavior and its relationship with the exertion perceived in Brazilian jiu-jitsu athletes. The authors found considerable HR elevation $(170,1+13.9 \mathrm{bpm})$ after the 10-minute simulated fight protocol, and PSE near maximum levels classified as 'heavy'. In the same respect, found an increase in HR after a simulated fight, as well as a large reduction in oxygen saturation capacity in individuals over 30 years, characterizing the effort as vigorous. Accordingly, the present study also found a positive association between HR values and PSE. This response is physiological, and the observed elevations are predictable and necessary to meet the metabolic demands required by the exercise. In this scenario, the submaximal PSE values verified in this study indicate that the Brazilian Jiu-Jitsu Parasport can be characterized as high intensity. This condition reflects on metabolic changes eventually triggered and the subsequent need for the application of recuperative protocols that help the return of body parameters at baseline levels.

Still regarding $H R$, studies $[11,22,23]$ that evaluated the effects of Brazilian jiu-jitsu on this variable showed high values during the fight protocol with subsequent return to baseline levels between the $2^{\text {nd }}$ and $5^{\text {th }}$ minutes post fight. In contrast, in the present study, the assessment was performed after the $12^{\text {th }}$ minute of recovery post fight, and yet the values had not fully returned to baseline. One possible explanation for this may be related to the participants' disability, since the lack of a limb, for example, may be responsible for higher accumulation of metabolites in the body segments, which even- 
tually would require harder work of the cardiovascular system to reestablish its functions at rest levels.

From the above, evidence show that the sporting characteristics of Brazilian jiu-jitsu practice triggers adaptations in the cardiovascular system and metabolism in general, to the detriment of the intensity required during sports, regardless of the time of its execution. However, although the increase in HR observed in this and other studies is physiological, the recovery time identified in this study in parathletes seems to be slower.

It is worth noting that the mentioned studies $[11,23,24]$ demonstrate different fighting protocols, different interval duration, different intensity and volume, which may cause different levels of cardiovascular responses. Accordingly, SPE always demonstrates a positive relationship with cardiac variables [11].

There are several studies investigating the practice of jiu-jitsu that have addressed, for example, functional and metabolic outcomes [25-29]. However, regarding specifically the massage application as a recuperative intervention in Brazilian jiu-jitsu, no study was found that verified its effects on the mentioned outcomes, which prevented comparisons and specific discussions. In this study, the massage application did not show significant efficacy on the recovery of cardiovascular outcomes. Nevertheless, we believe that specific protocols should be investigated with longer application time, considering the ease and accessibility resulting from the application of this technique associated with the good scientific evidence in other sports.

From the above, the outcomes demonstrate a specific diagnosis of physiological responses in a population, until then, never investigated by previous studies. In this scenario, due to the longer recovery time, the suggestion of recovery techniques is relevant in the context of restoring body homeostasis in a short time, improving performance, as well as reducing the risk of musculoskeletal injuries in the investigated athletes.

To the authors' knowledge, this is the first study that verifies cardiovascular outcomes and exertion perceived in response to the practice of Brazilian jiu-jitsu parasport. This may be due to the possibility of large variations between the types of disabilities, which may influence the heterogeneity of the evaluated group associated with the logistic difficulty mentioned above in grouping a large number of individuals with the same type of disability. However, it is necessary to consider this subject, and to understand the kinetic behavior in response to this sport practice, to assist the scientific and clinical community in the management of specific actions that assist in athletic performance and lower in- cidence of injuries in this population profile. It is reiterated that the outcomes presented should not be extrapolated to different population profiles.

The main limitation of this study was that long-term follow-up after the intervention was not performed. Further studies are needed to confirm whether the benefits eventually obtained by the protocol used are maintained and for how long. In addition, the small sample size limited the use of control group, placebo or other recovery techniques, for example.

On the other hand, strengths of this study are worth mentioning. Firstly, this study was designed from a high methodological quality because it was a controlled clinical trial that adopted allocation secrecy, which followed all items in the CONSORT checklist. Secondly, the procedures were performed in a field setting, identical to that used in competitive fight. In addition, the outcomes presented are unpublished, and constitute intrinsic potential under new perspectives and parameters related to parasports. It is pertinent that future studies address analysis of other biochemical markers, such as hormonal rate and cytokines, as well as the application of specific recovery techniques based on observed physiological responses in order to measure possible differences in physiological parameters after the fight.

\section{Conclusion}

The results presented allow to conclude that HR remained high in all participants after massage. A similar scenario was found for BP values, except for participant IV who recovered baseline levels. Also, there was subjective perception of high effort, close to strenuous levels of effort.

Finally, it is reiterated that changes in cardiovascular parameters represent an expected physiological adjustment to maintain energy levels during exercise. This data, associated with the outcome of perceived exertion, leads us to believe that the investigated modality is responsible for altering the body's homeostasis in the short term. Therefore, research in this field is relevant, suggesting specific interventional techniques for this population profile, in order to assist in the prescription of periodization and improve sports performance as well as reduce exposure on incidence of musculoskeletal injuries.

\section{Conflict of Interest Statement}

None declared. The authors declare that the research was conducted with no features that could be construed as a potential conflict of interest.

\section{References}

1. Reis FJ, Dias MD, Newlands F, Meziat-Filho N, Macedo AR (2015) Chronic low back pain and disability in Brazilian jiu-jitsu athletes. Phys Ther Sport 16: 340-343. 
2. Jones NB, Ledford E (2012) Strength and conditioning for Brazilian Jiu-jitsu. Strength Cond J 34: 60-69.

3. Coswig VS, Neves AHS, Del Vecchio FB (2013) Effects of duration practice in biochemical, hormonal and hematological parameters of people who practice Brazilian jiu-jitsu. Rev Andal Med Deporte 6: 15-21.

4. Andreato LV, Júlio UF, Gonçalves PVL, Del CJV, Hardt F, et al. (2015) Brazilian jiu-jitsu simulated the competition part II: physical performance, time-movement, technical-tactical analysis and perceptive responses. J Strength Cond Res 29: 2015-2025.

5. Moreira A, Franchini E, de Freitas CG, Schultz de Arruda AF, de Moura NR, et al. (2012) Salivary cortisol and immunoglobulin A responses to simulated and official Jiu-Jitsu matches. J Strength Cond Res 26: 2185-2191.

6. Lopes JSS, de Magalhães Neto AM, Alves PRL, Gonçalves LCO, de Almeida AC, et al. (2019) Kinetics of Muscle Damage Biomarkers at Moments Subsequent to a Fight in Brazilian Jiu-Jitsu Practice by Disabled Athletes. Front Physiol 10: 1055.

7. Branco BHM E Andreato LV, Alexandre A (2016) Effects of a Brazilian jiu-jitsu training session on physiological, biochemical, hormonal and perceptive responses. Arch Budo Sci Martial Arts Extrem Sports 12: 1.

8. Andreato LV, Franchini E, de Moraes SM, Pastório JJ, da Silva DF, et al. (2013) Physiological and Technical-tactical Analysis in Brazilian Jiu-jitsu Competition. Asian J Sports Med 4: 137-143.

9. Pinto JCBL, Loureiro ACC (2015) Análise de variáveis fisiológicas e perceptuais durante combates de Brazilian jiu-jitsu. Cinergis 16: 177-181.

10. James LP (2014) An Evidenced-Based Training Plan for Brazilian Jiu-Jitsu. Strength Cond J 36: 14-22.

11. Carneiro RW, Souza TMF, Assumpção CO, Neto JB, Asano RY, et al. (2013) Comportamento da frequência cardíaca e percepção subjetiva de esforço durante combate de jiu-jitsu brasileiro. RBPFEX 7: 98-102.

12. Franchini E, Takito MY, Pereira JNC (2003) Frequência cardíaca e força de preensão manual durante a luta de jiu-jitsu. Revista Digital.

13. Detanico D, Dellagrana RA, Athayde MSS, Kons RL, Góes A (2016) Effect of a Brazilian Jiu-jitsu-simulated tournament on strength parameters and perceptual responses. Sports Biomech, in press.

14. Machado AF, Micheletti JK, Lopes JSS, Vanderlei FM, Leal ECP Jr, et al. (2018) Phototherapy on management of creatine kinase activity in general versus localized exercise: systematic review and meta-analysis. Clin J Sport Med.

15. Branco BH, Fukuda DH, Andreato LV, Santos JF, Esteves JV, et al. (2016) The effects of hyperbaric oxygen therapy on post-training recovery in jiu-jitsu athletes. Plos One 9-11: 150-517.

16. Weerapong P, Hume PA, Kolt GS (2005) The mechanisms of massage and effects on performance, muscle recovery and injury prevention. Sports Med 35: 235-256.

17. Pastre CM, Bastos FdN, Netto Júnior J, Vanderlei LCM, Hoshi RA (2009) Métodos de recuperação pós-exercício: uma revisão sistemática. RBME 15: 138-144.

18. Hoffman MD, Badowski N, Chin J, Stuempfle KJ (2016) A Randomized Controlled Trial of Massage and Pneumatic Compression for Ultramarathon Recovery. J Orthop Sports Phys Ther 46: 320-326.

19. Hongsuwan C, Eungpinichpong W, Chatchawan U, Yamauchi $J$ (2015) Effects of Thai massage on physical fitness in soccer players. J Phys Ther Sci 27: 505-508.

20. Lopes JSS, Micheletti JK, Machado AF, Souto LR, de Lima HP, et al. (2018) Test- retest reliability of knee extensors endurance test with elastic resistance. PLoS One 13: e0203259.

21. Mantovani JN, Pizzo JE, dos Santos SM, de Souza CAP, Pastre CM, et al. (2018) Effects of massage as a recuperative technique on autonomic modulation of heart rate and cardiorespiratory parameters: a study protocol for a randomized clinical trial. Trials 19: 459.

22. Herdey AH, Fay CES, Bornschein C, Stein R (2003) Importância da análise da frequência cardíaca no teste de esforço. RBME 9: 147-254.

23. Andreato LV, Moraes SMF, Gomes TLM, Esteves JVDC, Andreato TV, et al. (2011) Estimated aerobic power, muscular strength and flexibility in elite Brazilian Jiu-Jitsu athletes. Sci Sports 26: 329-337.

24. Santos ALS, Caldas BP, Cruz MES, Silva JG, Santana MN, et al. (2018) Comportamento da frequência cardíaca e da saturação de oxigênio durante combate simulado de jiu-jitsu em praticantes acima de 30 anos de idade. RBPFEX 12: 333-338.

25. Andreato LV, Julio UF, Valeria LG, Panissa JVDC, Hardt FE, et al. (2015) Brazilian jiu-jitsu simulated competition part I metabolic, hormonal, cellular damage and heart rate responses. J Strength Cond Res 29: 2538-2549.

26. da Silva BV, Simim MA, Marocolo M, Franchini E, da Mota GR (2015) Optimal load for the peak power and maximal strength of the upper body in Brazilian Jiu-Jitsu athletes. J Strength Cond Res 29: 1616-1621.

27. Franchini E, Del Vecchio FB, Matsushigue KA, Artioli GG (2011) Physiological profiles of elite judo athletes. Sports Med 41: 147-166.

28. Fonseca LB, Brito CJ, Silva RJ, Silva-Grigoletto ME, da Silva WMJ, et al. (2016) Use of cold-water immersion to reduce muscle damage and delayed-onset muscle soreness and preserve muscle power in jiu-jitsu athletes. J Athl Train 51: $540-549$.

29. Lopes JSS, Machado AF, Cavina AP, Micheletti JK, Almeida AC, et al. (2019) Specific interventions for prevention of muscle injury in lower limbs: systematic review and meta-analysis. Fisioter Mov 32: 3224. 